\title{
Parity and total, ischemic heart disease and stroke mortality. The Adventist Health Study, 1976-1988
}

\author{
Bjarne Koster Jacobsen • Synnøve Fønnebø Knutsen • \\ Keiji Oda $\cdot$ Gary Ernest Fraser
}

Received: 3 December 2009/Accepted: 11 June 2011/Published online: 24 June 2011

(C) The Author(s) 2011. This article is published with open access at Springerlink.com

\begin{abstract}
In a prospective study with information about life style and reproductive factors, we assessed the relationship between parity and total, ischemic heart disease, and stroke mortality. The large majority of the 19,688 California Seventh-day Adventist women included did not smoke or drink alcohol, 31 percent never ate meat and physical activity was relatively high. Cox proportional hazard analysis was conducted with parity as the main independent variable and with adjustment for a number of other possible confounders. During follow-up from 1976 through 1988, there were 3,122 deaths; 782 deaths from ischemic heart disease and 367 deaths due to stroke. There were no relationships between parity and total mortality $(P$-value for overall effect of parity $=0.32)$. Grand multiparous women ( $>4$ children) had somewhat increased ischemic heart disease mortality $(\mathrm{MRR}=1.45,95 \% \mathrm{CI}$ : $1.15,1.84)$ before adjustment for educational level. After adjustment for educational level and marital status, there were no relationship with mortality from ischemic heart disease $(P=0.29)$ or stroke $(P=0.72)$. In parous women, there were, after adjustment for age at first delivery, some suggestions of an increased total mortality in women with
\end{abstract}

B. K. Jacobsen $(\bowtie)$

Department of Community Medicine, University of Troms $\varnothing$, 9037 Troms $\varnothing$, Norway

e-mail: bjarne.jacobsen@uit.no

S. F. Knutsen - K. Oda · G. E. Fraser

Department of Epidemiology and Biostatistics, School of Public Health, Loma Linda University, Loma Linda, CA 92350, USA

G. E. Fraser

Center for Health Research, School of Public Health, Loma

Linda University, Loma Linda, CA 92350, USA one child. For ischemic heart disease and stroke mortality, no associations were found. Stratified and adjusted analyses confirmed these results. Thus, we found no consistent relationships between parity and total, ischemic heart disease or stroke mortality. However, a longer follow-up would have been helpful and the conclusions may be somewhat influenced by the lifestyle of the women included.

Keywords Parity · Reproductive history · Mortality · Myocardial infarction - Stroke
Abbreviations
CI Confidence interval
MRR Mortality rate ratio

\section{Introduction}

Childbirth may influence the health of the mother both in the short and long term. The "disposable soma" theory proposes a trade off between fecundity and longevity, such that women who have more children are likely to have shorter lives [1]. The empirical evidence for this theory is limited [2] although the analyses of some large historical databases may suggest an effect of high parity [3].

The possible relationship between parity and mortality has recently been reviewed [2, 4-7] and some of the most relevant issues are summarized in the following. Healthy women may have higher fertility, and an inverse relationship between parity and mortality is thus expected. The mortality may, however, increase with parity as the women become depleted with multiple pregnancies, particularly if the time between the pregnancies is short. A reflection of 
this is the saying that "A child costs the mother a tooth". High parity confers substantially reduced risk of breast cancer, but may increase the risk of cardiovascular diseases. Age at first delivery is related to parity and an early delivery (especially during the teens) has in most studies been found to reduce breast cancer risk, but increase total and cardiovascular mortality [8] although the reasons may not be entirely biological [9]. Finally, health problems which emerge during pregnancy (gestational diabetes, proteinuria and hypertension) may also have long term consequences [10].

There are several large studies of the relationship between parity and total mortality in women in contemporary populations [4]. Recently, at least three relatively large studies have been published [11-14]. However, only one had information on smoking habits, body mass index and age at menarche [12], and previous studies have lacked comprehensive information about other aspects of life style such as physical activity, alcohol and dietary habits, religious activity, as well as female specific factors (e.g., age at menopause, use of oral contraceptives or hormone replacement therapy).

Several studies have analysed the possible relationships between parity and cardiovascular disease risk. Some of the older studies $[15,16]$ and a large follow-up of more than 500,000 American women [17] reported relatively weak, if any, relationships between parity and ischemic heart disease mortality. A recent case-case control study seems to confirm these findings [18]. Results with regard to stroke also differ between studies [12, 19-22].

Therefore, we present the results from 12-year mortality follow-up of 12,688 Californian Seventh-day Adventist post-menopausal women of which 3,122 died. The great majority of women in this population were non smokers and did not drink alcohol, 31 percent did not eat meat and physical activity was relatively high. Furthermore, information about a number of possible confounders was available for each woman.

\section{Materials and methods}

In 1974, a census questionnaire was mailed to the head of all identified Seventh-Day Adventist households in California. Sixty percent of the households returned this questionnaire. Two years later, 75 percent of the white, non-Hispanic Seventh-Day Adventists aged 25 years and older, who had previously been identified by the Census Questionnaire returned a new postal questionnaire (the Lifestyle Questionnaire) [23, 24].

This questionnaire included questions concerning pregnancies and births. Women who stated that they ever had been pregnant were asked "How many pregnancies that resulted in a child born alive at term" and "How many pregnancies resulted in a child born alive but premature". Parous women were also asked how old they were when they delivered their first child. We identified 12,688 postmenopausal women who had given information about how many live born children they had delivered, both prematurely and at term, 12,478 women who indicated that their menstrual periods had completely stopped and 210 women who did not answer this question, but were more than 55 years of age at enrollment. Parity was categorized into $0,1,2$ (the reference group), 3,4 and 5 or more children.

Information about possible confounders was obtained from the questionnaires. Height and weight were selfreported and body mass index was computed as weight in kilograms divided by the square of height in meters $(\mathrm{kg} /$ $\mathrm{m}^{2}$ ). Two different variables (frequency of church attendance and religious activity in the Adventist church) were used to measure religious activity.

The follow-up started when the Lifestyle Questionnaire was returned and ended when the respondent died or on December 31, 1988. Validity studies indicate that at most three to four percent of deaths have been missed [23]. Any of the ICD-9 codes for underlying cause of death 410-414 and 430-438 was used as the definition of ischemic heart disease and stroke, respectively.

Possible confounders were categorized as shown in Table 1. Associations between the proportion of women who were nulliparous (i.e., not given birth to a live born child) and possible confounders (shown in Table 1) were adjusted for age. The age-adjusted values were computed based on a logistic regression model. Relationships between parity and these variables were adjusted for age by analysis of variance including age group as a factor in the model. Relationships between parity and mortality were investigated in proportional hazard regression models using attained age as the time variable. The proportional hazard assumption was tested by checking the statistical significance of the product term between parity and attained age. In some analyses, we included a second order term in order to test for non-linear associations between parity and mortality.

A number of stratified analyses were conducted. In particular, in many analyses we restricted the population to parous women and adjusted for age at first delivery. Due to missing values, the number of women included in the analyses changes somewhat from one analysis to the next.

The $P$ values given in Table 1 are for the linear relationship between parity and the different independent variables. The $P$ values given in Tables 2, 3, 4, 5 are for the overall effect of parity as a categorical variable. Analyses were performed using SAS Software [25]. 
Table 1 Relationships between different demographic and life style variables and parity

\begin{tabular}{|c|c|c|c|c|c|}
\hline & Number of women $(\%)$ & Percent nulliparous & $P$-value ${ }^{\mathrm{a}}$ & Mean parity & $P$-value ${ }^{\mathrm{a}}$ \\
\hline \multicolumn{6}{|l|}{ Age at entry (years) } \\
\hline$<50$ & $1590(12.5)$ & 12.1 & \multirow[t]{5}{*}{$<0.0001$} & 2.47 & \multirow[t]{5}{*}{$<0.0001$} \\
\hline $50-59$ & $3,268(25.8)$ & 13.9 & & 2.41 & \\
\hline $60-69$ & 3,765 (29.7) & 21.6 & & 1.98 & \\
\hline $70-79$ & $2,630(20.7)$ & 23.5 & & 2.12 & \\
\hline $80+$ & $1,435(11.3)$ & 21.3 & & 2.43 & \\
\hline \multicolumn{6}{|l|}{ Marital status } \\
\hline Never married & $560(4.4)$ & 97.7 & \multirow[t]{4}{*}{$<0.0001$} & 0.10 & \multirow[t]{4}{*}{$<0.0001$} \\
\hline Married & $8,110(64.3)$ & 15.0 & & 2.33 & \\
\hline Widowed & $2,838(22.5)$ & 14.0 & & 2.51 & \\
\hline Divorced/separated & $1,097(8.7)$ & 16.3 & & 2.35 & \\
\hline \multicolumn{6}{|c|}{ Level of education (years) } \\
\hline$<9$ & $1,600(15.5)$ & 11.9 & \multirow[t]{6}{*}{$<0.0001$} & 2.84 & \multirow[t]{6}{*}{$<0.0001$} \\
\hline $9-11$ & $1,943(18.8)$ & 13.9 & & 2.56 & \\
\hline 12 & $3,173(30.7)$ & 17.2 & & 2.19 & \\
\hline $13-15$ & $2,100(20.3)$ & 17.6 & & 2.13 & \\
\hline 16 & $1,086(10.5)$ & 28.7 & & 1.77 & \\
\hline$>16$ & $422(4.1)$ & 37.3 & & 1.56 & \\
\hline \multicolumn{6}{|l|}{ Smoking status } \\
\hline Current smoker & $192(1.5)$ & 23.1 & \multirow[t]{3}{*}{0.039} & 2.05 & \multirow[t]{3}{*}{0.018} \\
\hline Past smoker & $1,656(13.3)$ & 19.8 & & 2.22 & \\
\hline Never smoked & $10,560(85.1)$ & 18.2 & & 2.29 & \\
\hline \multicolumn{6}{|l|}{ Level of exercise } \\
\hline No exercise & 4,093 (33.0) & 18.2 & \multirow[t]{4}{*}{0.62} & 2.26 & \multirow[t]{4}{*}{0.99} \\
\hline Some exercise & $1,347(10.9)$ & 19.7 & & 2.24 & \\
\hline Low-level exercise & $2,216(17.9)$ & 18.2 & & 2.35 & \\
\hline High-level exercise & $4,735(38.2)$ & 18.8 & & 2.25 & \\
\hline \multicolumn{6}{|c|}{ Body mass index $\left(\mathrm{kg} / \mathrm{m}^{2}\right)$} \\
\hline$<20$ & $1,294(11.3)$ & 25.6 & \multirow[t]{4}{*}{$<0.0001$} & 1.89 & \multirow[t]{4}{*}{$<0.0001$} \\
\hline $20-24$ & $5,601(48.8)$ & 18.9 & & 2.21 & \\
\hline $25-29$ & $3,220(28.1)$ & 16.3 & & 2.43 & \\
\hline $30+$ & $1,361(11.9)$ & 16.3 & & 2.60 & \\
\hline \multicolumn{6}{|l|}{ Meat consumption } \\
\hline Never & $3,689(31.4)$ & 21.6 & \multirow[t]{4}{*}{$<0.0001$} & 2.17 & \multirow[t]{4}{*}{$<0.0001$} \\
\hline$<1 /$ week & $2,769(23.6)$ & 18.8 & & 2.30 & \\
\hline $1-4 /$ week & $2,511(21.4)$ & 16.9 & & 2.33 & \\
\hline$>4 /$ week & $2,781(23.7)$ & 16.6 & & 2.31 & \\
\hline \multicolumn{6}{|c|}{ Childhood vegetarianism } \\
\hline Non-vegetarian & $7,886(87.6)$ & 18.5 & 0.001 & 2.27 & $<0.0001$ \\
\hline Vegetarian & $1,117(12.4)$ & 22.8 & & 2.06 & \\
\hline Alcohol consumptior & & & & & \\
\hline Never & $10,705(93.3)$ & 18.8 & 0.22 & 2.27 & 0.30 \\
\hline Ever & $765(6.7)$ & 16.9 & & 2.20 & \\
\hline Age at menarche (ye & & & & & \\
\hline$<12$ & 2,338 (18.4) & 18.7 & 0.65 & 2.26 & 0.36 \\
\hline $12-13$ & $6,190(48.8)$ & 18.7 & & 2.27 & \\
\hline $14-15$ & $3,368(26.5)$ & 18.0 & & 2.29 & \\
\hline$>15$ & $792(6.2)$ & 18.9 & & 2.32 & \\
\hline
\end{tabular}


Table 1 continued

\begin{tabular}{|c|c|c|c|c|c|}
\hline & Number of women $(\%)$ & Percent nulliparous & $P$-value ${ }^{\mathrm{a}}$ & Mean parity & $P$-value \\
\hline \multicolumn{6}{|c|}{ Age at first delivery (years) } \\
\hline$<18$ & 1,091 (10.7) & - & & 3.50 & \multirow[t]{6}{*}{$<0.0001$} \\
\hline $19-20$ & $1,864(18.2)$ & - & & 3.16 & \\
\hline $21-22$ & $1,871(18.3)$ & - & & 3.01 & \\
\hline $23-24$ & $1,682(16.5)$ & - & & 2.76 & \\
\hline $25-28$ & $2,105(20.6)$ & - & & 2.49 & \\
\hline$>28$ & $1,608(15.7)$ & - & & 1.98 & \\
\hline \multicolumn{6}{|c|}{ Age at menopause (years) } \\
\hline$<40$ & $2,578(21.6)$ & 20.1 & \multirow[t]{3}{*}{0.018} & 2.10 & \multirow[t]{3}{*}{$<0.0001$} \\
\hline $40-49$ & $4,971(41.7)$ & 18.4 & & 2.30 & \\
\hline $50+$ & $4,376(36.7)$ & 17.6 & & 2.40 & \\
\hline \multicolumn{6}{|l|}{ Type of menopause } \\
\hline Hysterectomy & $5,497(45.4)$ & 15.6 & \multirow[t]{3}{*}{$<0.0001$} & 2.33 & \multirow[t]{3}{*}{$<0.0001$} \\
\hline Natural & $6,270(51.8)$ & 20.6 & & 2.25 & \\
\hline Other & $343(2.8)$ & 27.5 & & 1.94 & \\
\hline \multicolumn{6}{|l|}{ Oral contraceptives } \\
\hline Never taken & $10,405(89.5)$ & 19.2 & \multirow[t]{2}{*}{$<0.0001$} & 2.27 & \multirow[t]{2}{*}{0.005} \\
\hline Current/past user & $1,221(10.5)$ & 11.4 & & 2.43 & \\
\hline \multicolumn{6}{|c|}{ Hormone replacement therapy $(H R T)$} \\
\hline Never taken & $5,140(42.7)$ & 17.5 & \multirow[t]{2}{*}{0.017} & 2.37 & \multirow[t]{2}{*}{$<0.0001$} \\
\hline Current/past user & $6,894(57.3)$ & 19.3 & & 2.18 & \\
\hline \multicolumn{6}{|l|}{ Church attendance } \\
\hline$<3 \mathrm{x} / \mathrm{mo}$ & $1,998(15.9)$ & 18.7 & \multirow[t]{2}{*}{0.77} & 2.29 & \multirow[t]{2}{*}{0.77} \\
\hline $3-4 x / m o$ & $10,558(84.1)$ & 18.5 & & 2.28 & \\
\hline \multicolumn{6}{|l|}{ Religious activity } \\
\hline Inactive & $2,056(18.8)$ & 18.7 & \multirow[t]{4}{*}{0.14} & 2.32 & \multirow[t]{4}{*}{0.63} \\
\hline Not very active & $3,378(31.0)$ & 19.2 & & 2.25 & \\
\hline Active & $3,476(31.9)$ & 18.1 & & 2.26 & \\
\hline Most active & $2,003(18.4)$ & 17.3 & & 2.29 & \\
\hline
\end{tabular}

The Adventist Health Study, 1976-1988

a $P$ values for the linear relationship (if more than two groups) between parity and the different independent variables

\section{Results}

The mean (standard deviation) and median parity of the women included in our analysis were 2.2 (1.7) and 2, respectively. A total of 19 percent of the women were nulliparous, 10 percent had given birth to five or more children; only 0.1 percent had 10 or more children. The mean age at start of follow-up was 64 years (range 27-100). The mean follow-up period was 10.7 years (range 0-12 years).

Table 1 gives the age-adjusted relationships between different possible confounders and parity as well as the proportion of the women who were nulliparous. We found relationships for marital status, educational level, smoking, body mass index, meat consumption as well as some reproductive variables (age at first birth delivery and menopause, type of menopause and use of oral contraceptives or hormone replacement therapy (HRT)).

Less than 2 percent of the women were current smokers, and they were therefore merged with past smokers $(13 \%)$ in most of the later analyses. There was a strong inverse relationship between age at first delivery and parity. The relatively high proportion of women with an early menopause ( 22 percent aged $<40$ years) was due to surgical menopause; 45 percent of the women indicated that the menstruation stopped because of a hysterectomy. We also noted that both in women with a natural menopause ("Natural change of life") and women with a surgical menopause, age at menopause was positively related to parity (data not shown).

A total of 3,122 women died during follow-up. The mean age at death was 81.8 years. Essentially no 
Table 2 Relationships between parity and total mortality in all women

The Adventist Health Study, 1976-1988

a In ever married women, adjusted for marital status

b $P$ values for the overall effect of parity as a categorical variable

\begin{tabular}{|c|c|c|c|c|c|c|c|c|}
\hline \multirow[t]{2}{*}{ Parity } & \multicolumn{2}{|l|}{ No. of } & \multicolumn{2}{|c|}{ All women } & \multicolumn{2}{|c|}{ Ever married } & \multicolumn{2}{|c|}{ Ever married $^{\mathrm{a}}$} \\
\hline & Women & Deaths & MRR & $95 \% \mathrm{CI}$ & MRR & $95 \% \mathrm{CI}$ & MRR & $95 \% \mathrm{CI}$ \\
\hline 0 & 2,383 & 661 & 1.03 & $0.92,1.15$ & 1.05 & $0.94,1.18$ & 1.05 & $0.94,1.18$ \\
\hline 1 & 1,985 & 548 & 1.10 & $0.99,1.24$ & 1.10 & $0.98,1.23$ & 1.10 & $0.98,1.23$ \\
\hline 2 & 3,293 & 685 & 1.00 & & 1.00 & & 1.00 & \\
\hline 3 & 2,423 & 480 & 1.00 & $0.89,1.13$ & 1.00 & $0.89,1.12$ & 1.00 & $0.89,1.12$ \\
\hline 4 & 1,386 & 336 & 1.07 & $0.94,1.22$ & 1.06 & $0.93,1.21$ & 1.05 & $0.92,1.20$ \\
\hline $5+$ & 1,218 & 412 & 1.11 & $0.98,1.26$ & 1.12 & $0.99,1.26$ & 1.11 & $0.98,1.25$ \\
\hline$P$-value ${ }^{\mathrm{b}}$ & & & 0.32 & & 0.36 & & 0.44 & \\
\hline
\end{tabular}

relationship was found a between parity and total mortality although indications for an increased mortality in women with more than 4 children may be suggested (Table 2). Including stillbirths in the number of births (16 women reported only still births and no live births), gave very similar results as those presented in Table 2. Additional adjustment for birth cohort did not influence the association.

We performed a number of stratified analyses and analyses of the relationship between parity and total mortality adjusted for possible confounders. Although the point estimates did change to some extent, for example when adjusting for level of education, these adjustments did not indicate any relationship between parity and total mortality. This was also the case when the relationship was adjusted for a number of possible confounders (marital status, education, ever smoking, body mass index, meat consumption, childhood vegetarianism, age at menopause and type of menopause, and ever use of oral contraceptives or hormone replacement therapy) in concert. In no stratum of this population did we find any notable relationship between parity and mortality (results not shown). The only exception might be that a non-linear, U-formed, relationship between parity and total mortality seems to be present in women who eat meat at least weekly $(P$-value for second

Table 3 Relationships between parity and total mortality in ever married, parous women with known age at first delivery

\begin{tabular}{|c|c|c|c|c|c|c|}
\hline \multirow[t]{2}{*}{ Parity } & \multicolumn{2}{|c|}{ Number of } & \multicolumn{2}{|c|}{$\begin{array}{l}\text { Not adjusted for } \\
\text { age at } 1 \text { st birth }\end{array}$} & \multicolumn{2}{|c|}{$\begin{array}{l}\text { Adjusted for age } \\
\text { at } 1 \text { st birth }\end{array}$} \\
\hline & Women & Deaths & MRR & $95 \% \mathrm{CI}$ & MRR & $95 \% \mathrm{CI}$ \\
\hline 1 & 1,939 & 530 & 1.09 & $0.97,1.22$ & 1.11 & $0.99,1.25$ \\
\hline 2 & 3,246 & 667 & 1.00 & & 1.00 & \\
\hline 3 & 2,393 & 465 & 1.00 & $0.89,1.13$ & 0.97 & $0.86,1.10$ \\
\hline 4 & 1,365 & 328 & 1.06 & $0.93,1.21$ & 1.02 & $0.89,1.16$ \\
\hline $5+$ & 1,198 & 402 & 1.11 & $0.98,1.26$ & 1.03 & $0.91,1.17$ \\
\hline$P$-value ${ }^{\mathrm{a}}$ & & & 0.34 & & 0.28 & \\
\hline
\end{tabular}

The Adventist Health Study, 1976-1988

${ }^{a} P$ values for the overall effect of parity as a categorical variable order term for parity $=0.045$ ). No association was found between parity and mortality in women with low or high education, in women with normal weight (body mass index $<25$ ) or in overweight and obese women (body mass index $\geq 25$ ). Adjustments for smoking (current, previous or never smoker) did not influence our results and no association was found when restricting the analyses to women who never have smoked. Furthermore, age at menarche or menopause, type of menopause, use of oral contraceptives or hormone replacement therapy or religious activity had no impact on the relationship between parity and total mortality.

Table 3 gives the results for the follow-up of 10,141 ever married parous women with known age at first delivery. There were 2,392 deaths. We found no consistent overall relationship between parity and total mortality, but women with one child only may have slightly increased mortality (the $P$-value for a second order term for parity (categorized as in Table 3) was $P=0.05$ ). We found no difference in the effect of parity on mortality in women with a relatively early first delivery (aged 22 or less) and women who were older when they had their first child. Similarly to the analyses that including all women, we also performed a number of adjusted (including adjustment for a number of possible confounders in concert as described above) and stratified analyses in this group of parous women. In all of these analyses, we adjusted for age at first delivery. The results demonstrated no important confounding or effect modification by any of the considered variables, including type of menopause.

In total, there were 782 and 367 deaths from ischemic heart disease and stroke, respectively. Initially, we found a relationship between parity and ischemic heart disease mortality as women with high parity had an increased risk in $(>4$ children) $(\mathrm{MMR}=1.45,95 \% \mathrm{CI}: 1.15,1.84)$. However, adjustments for educational level did reduce the relative mortality rate in women with high parity $(>4$ children) from 1.45 to 1.26 (95\% CI: $0.96,1.66$ ).

Thus, after adjustments for educational level, no relationships were found between parity and ischemic heart 
Table 4 Relationships between parity and mortality from ischemic heart disease and stroke in ever married women

\begin{tabular}{|c|c|c|c|c|c|c|c|}
\hline \multirow[t]{2}{*}{ Parity } & \multirow[t]{2}{*}{ No. of women } & \multicolumn{3}{|c|}{ Ischemic heart disease } & \multicolumn{3}{|l|}{ Stroke } \\
\hline & & No. of deaths & MRR & $95 \% \mathrm{CI}$ & No. of deaths & MRR & $95 \% \mathrm{CI}$ \\
\hline 0 & 1,426 & 98 & 1.13 & $0.87,1.48$ & 37 & 0.84 & $0.55,1.27$ \\
\hline 1 & 1,598 & 97 & 1.06 & $0.81,1.38$ & 45 & 1.02 & $0.69,1.52$ \\
\hline 2 & 2,681 & 117 & 1.00 & & 56 & 1.00 & \\
\hline 3 & 2,031 & 79 & 0.88 & $0.66,1.18$ & 46 & 1.15 & $0.78,1.70$ \\
\hline 4 & 1,142 & 66 & 1.09 & $0.80,1.48$ & 29 & 1.04 & $0.66,1.63$ \\
\hline $5+$ & 985 & 99 & 1.26 & $0.96,1.66$ & 31 & 0.85 & $0.54,1.34$ \\
\hline$P$-value ${ }^{\mathrm{a}}$ & & & 0.29 & & & 0.72 & \\
\hline
\end{tabular}

Adjusted for marital status and level of education. The Adventist Health Study, 1976-1988

${ }^{\text {a }} P$ values for the overall effect of parity as a categorical variable

Table 5 Relationships between parity and mortality from ischemic heart disease and stroke in parous women with known age at first delivery

\begin{tabular}{|c|c|c|c|c|c|c|c|}
\hline \multirow[t]{2}{*}{ Parity } & \multirow[t]{2}{*}{ No. of women } & \multicolumn{3}{|c|}{ Ischemic heart disease } & \multicolumn{3}{|l|}{ Stroke } \\
\hline & & No. of deaths & MRR & $95 \% \mathrm{CI}$ & No. of deaths & MRR & $95 \% \mathrm{CI}$ \\
\hline 1 & 1,587 & 97 & 1.13 & $0.86,1.48$ & 45 & 1.05 & $0.71,1.56$ \\
\hline 2 & 2,663 & 112 & 1.00 & & 55 & 1.00 & \\
\hline 3 & 2,020 & 77 & 0.87 & $0.65,1.17$ & 46 & 1.16 & $0.78,1.73$ \\
\hline 4 & 1,134 & 66 & 1.08 & $0.79,1.47$ & 27 & 0.97 & $0.60,1.55$ \\
\hline $5+$ & 980 & 98 & 1.21 & $0.91,1.61$ & 30 & 0.82 & $0.51,1.31$ \\
\hline$P$-value ${ }^{\mathrm{a}}$ & & & 0.26 & & & 0.70 & \\
\hline
\end{tabular}

Adjusted for level of education and age at first delivery in ever married women. The Adventist Health Study, 1976-1988

${ }^{a} P$-values for the overall effect of parity as a categorical variable

disease mortality ( $P$-values for the overall effect of parity as a categorical variable $=0.29$ ) (Table 4$)$. The numbers of women included in Table 4 are lower than those presented in Table 2 because the analyses are restricted to ever married women with information about educational level (missing for 2,183 ever married women). No relationship was found. A non-linear relationship may be suggested; the $P$-value for second order term parity (categorized as in Table 4) was 0.13 . Also for the relationship between parity and ischemic heart disease mortality, we performed a number of adjusted and stratified analyses, also adjustment for a number of possible confounders in concert. However, we found no important confounding or effect modification by any of the considered variables. The only exception was a suggestion of a U-formed association between parity and ischemic heart disease mortality when adjusted for age at menopause, but this relationship was found only in women who did not have a natural menopause ( $P$-value for second order term for parity $=0.015$ ).

Similarly, no relationship whatsoever was found between parity and stroke mortality with or without adjustment for marital status or educational level. Table 4 displays the relationship between parity and stroke mortality in ever married women and adjusted for marital status and level of education. Further adjusted and stratified analyses (as described above for total mortality) did not indicate any important confounding or interactions except for a possible interaction by educational level as stroke mortality in women with $>12$ years of education was highest in women with low parity (no or one child) and 5 or more children.

Table 5 shows the results for the relationships between parity and ischemic heart and stroke mortality in ever married, parous women with adjustments for age at first delivery, marital status and level of education. No significant relationships were found for ischemic heart disease or stroke mortality. Further adjusted and stratified analyses (as described above for total mortality) did not indicate any important confounding or interactions in the analyses of the relationships between parity and ischemic heart disease or stroke mortality in parous women except the relationships described above. 


\section{Discussion}

We find little evidence for an important relationship between parity and total as well as ischemic heart and stroke mortality in this 12-year follow-up of 12,000 Californian Seventh-day Adventists women. Childless women or women with many children do not have mortality that differs much from women with two children. In parous women, however, and after adjustment for age at first delivery, the results may suggest that a slightly (10\%) higher total mortality in women with one child compared to women with two or more children.

In order to ensure that the women had ended their childbearing period, only post-menopausal women were included in the study. However, due to the high proportion of women with a hysterectomy (45 percent), it is possible that some of the younger women have functional ovaries. We have, however, performed stratified analyses, and there were no associations between parity and mortality in women who reported a natural menopause. We included only live births in our analyses. However, the results given in Table 2 were only marginally changed if the number of stillbirths were included in the number of births.

In their review of the literature concerning the relationships between parity and total mortality, Hurt and coworkers [4] reported that the results varied to a great degree across studies, but results from most contemporary populations suggest that compared to women with two children, nulliparous women have a somewhat (20 percent) increased mortality and that also multiparous women have a slightly increased mortality. The confidence intervals for the point estimates presented in Table 2 seem compatible with such weak relationships. A recent analysis of three historical populations gives support to a weak positive relationship between parity and mortality, but also gives support to a possible interaction with age at last birth (a high age at last birth reducing mortality) [3] .

It is possible that chronic diseases during the childbearing years may have reduced the parity, reflected in increased mortality in women with few children. Although the women gave information about a number of different chronic diseases in the self-administered questionnaire, we lack information about when these health problems first were diagnosed. Therefore, we cannot further evaluate any such confounding. Similarly, we are not able to study any possible interaction with pregnancy complications (such as preeclampsia, hypertension or gestational diabetes) [26]. Furthermore, height and weight of the women at start of follow-up was self-reported. Thus, body mass index may have been underestimated even though self-reported body weight has been found to correlate strongly (0.95) with measured weight in a validation study [27] in the same Adventist population. We must also expect some non- differential misclassification with regard to cause of death in the analyses of relationships between parity and ischemic heart disease and stroke mortality.

The study has, however, some important strengths, mainly related to the control for possible confounders. Cigarette smoking must be expected to be a potential important confounder. Current smoking, however, was very uncommon in this Adventist population (2\%), and only $13 \%$ were past smokers. On average, women who had smoked previously, had smoked 13 years before enrolment. However, adjustments or stratification for past smoking did not influence our results. A previous Finnish study with 1,075 deaths in 12,002 parous women also included adjustment for smoking [12]. It may be a weakness of the present study that the dietary habits and smoking history of a relatively large proportion of the women included in the analyses differ from most American women, although the study sample also includes women who eat meat several times a week and even some previous smokers. The external validity of the results can therefore be discussed. It would also have been a strength if the follow-up period had been longer, thus including a higher number of deaths in the analyses.

There was a relatively strong positive relationship between parity and overweight. The mechanism may be that women tend to gain weight after pregnancy, although this has recently been questioned [28]. As a high body mass index increases mortality [29], body mass index may be a relevant confounder, but adjustment for body mass index when assessing the relationships between parity and mortality did not influence the relationship.

Vegetarianism reduces mortality [30] and nearly one in three of the included Seventh-day Adventist women reported that they never ate meat. There were some relationships between meat eating and parity (Table 1), but adjustments for meat eating did not influence our conclusions.

There were some indications of a stronger, non-linear relationship between parity and total mortality in women who ate meat weekly. Similarly, we found a non-linear relationship between parity and stroke mortality in parous women with $>12$ years of education. However, due to the many stratified analyses that have been undertaken; we do not put too much emphasis on these findings.

None of the possible confounders adjusted for did influence our findings of essentially no important relationship between parity and total mortality when including also nulliparous women. In parous women, however, there were indications of a non-linear relationship with an increased mortality in women with only one child, but the association is not strong and the $P$-value for the secondorder term was 0.05 . Regarding ischemic heart disease mortality, adjustments for educational level had an impact. 
However, the relationship was weak both before and after such adjustments.

In summary, we find essentially no consistent association between parity and total mortality as well as ischemic heart and stroke mortality although the conclusions may be somewhat influenced by the lifestyle of the women included. We cannot exclude relatively minor effects of parity on total or ischemic heart disease mortality, but the size of the study, including more than 3,000 deaths, seems to exclude strong effects.

Acknowledgments The data collection for this study was supported by grant 2RO1-CA14703 from the National Cancer Institute.

Conflicts of interest None declared.

Open Access This article is distributed under the terms of the Creative Commons Attribution Noncommercial License which permits any noncommercial use, distribution, and reproduction in any medium, provided the original author(s) and source are credited.

\section{References}

1. Westendorp RGJ, Kirkwood TBL. Human longevity at the cost of reproductive success. Nature. 1998;396:743-6.

2. Le Bourg E. Does reproduction decrease longevity in human beings? Ageing Res Rev. 2007;6:141-9.

3. Gagnon A, Smith KR, Tremblay M, et al. Is there a trade-off between fertility and longevity? A comparative study of women from three large historical databases accounting for mortality selection. Am J Hum Biol. 2009;21:533-40.

4. Hurt LS, Ronsmans C, Thomas SL. The effect of number of births on women's mortality: systematic review of the evidence for women who have completed their childbearing. Popul Stud (Camb). 2006;60:55-71.

5. Kendig H, Dykstra PA, van Gaalen RI, et al. Health of aging parents and childless individuals. J Fam Issues. 2007;28:1457-86.

6. Alter G, Dribe M, Van Poppel F. Widowhood, family size, and postreproductive mortality: a comparative analysis of three populations in nineteenth-century Europe. Demography. 2007;44:785-806.

7. Jasienska G. Reproduction and lifespan: trade-offs, overall energy budgets, intergenerational costs, and costs neglected by research. Am J Hum Biol. 2009;21:524-32.

8. Henretta JC. Early childbearing, marital status, and women's health and mortality after age 50. J Health Soc Behav. 2007; 48:254-66.

9. Hardy R, Lawlor DA, Black S, et al. Number of children and coronary heart disease risk factors in men and women from a British birth cohort. BJOG. 2007;114:721-30.

10. Wikström AK, Haglund B, Olovsson M, et al. The risk of maternal ischaemic heart disease after gestational hypertensive disease. BJOG. 2005;112:1486-91.

11. Grundy E, Kravdal $\varnothing$. Reproductive history and mortality in late middle age among Norwegian men and women. Am J Epidemiol. 2008;167:271-9.
12. Koski-Rahikkala H, Pouta A, Pietiläinen K, et al. Does parity affect mortality among parous women? J Epidemiol Community Health. 2006;60:968-73.

13. Jaffe DH, Neumark YD, Eisenbach Z, et al. Parity-related mortality: shape of association among middle-aged and elderly men and women. Eur J Epidemiol. 2009;24:9-16.

14. Grundy E. Women's fertility and mortality in late mid life: a comparison of three contemporary populations. Am J Hum Biol. 2009;21:541-7.

15. Green A, Beral V, Moser K. Mortality in women in relation to their childbearing history. BMJ. 1988;297:391-5.

16. Ness RB, Harris T, Cobb J, et al. Number of pregnancies and the subsequent risk of cardiovascular disease. $\mathrm{N}$ Engl J Med. 1993;328:1528-33.

17. Steenland K, Lally C, Thun M. Parity and coronary heart disease among women in the American Cancer Society CPS II population. Epidemiology. 1996;7:641-3.

18. Bertuccio P, Tavani A, Gallus S, et al. Menstrual and reproductive factors and risk of non-fatal acute myocardial infarction in Italy. Eur J Obstet Gynecol Reprod Bio. 2007;134:67-72.

19. Qureshi AI, Giles WH, Croft JB, et al. Number of pregnancies and risk for stroke and stroke subtypes. Arch Neurol. 1997;54:203-6.

20. Hinkula M, Kauppila A, Nayha S, et al. Cause-specific mortality of grand multiparous women in Finland. Am J Epidemiol. 2006;163:367-73.

21. Yang L, Kuper H, Sandin S, et al. Reproductive history, oral contraceptive use, and the risk of ischemic and hemorrhagic stoke in a cohort study of middle-aged Swedish women. Stroke. 2009;40:1050-8.

22. Zhang X, Shu XO, Gao YT, et al. Pregnancy, childrearing, and risk of stroke in Chinese women. Stroke. 2009;40:2680-4.

23. Beeson WL, Mills PK, Phillips RL, et al. Chronic disease among seventh-day adventists, a low-risk group. Rationale, methodology, and description of the population. Cancer. 1989;64:570-81.

24. Snowdon DA, Kane RL, Beeson WL, et al. Is early natural menopause a biologic marker of health and aging? Am J Public Health. 1989;79:709-14.

25. SAS Institute Inc. SAS/STAT user's guide, Version 9. Cary, NC: SAS Institute; 2004.

26. Catov JM, Newman AB, Sutton-Tyrrell K, et al. Parity and cardiovascular disease risk among older women: how do pregnancy complications mediate the association? Ann Epidemiol. 2008; 18:873-9.

27. Singh PN, Fraser GE. Dietary risk factors for colon cancer in a low-risk population. Am J Epidemiol. 1998;148:761-74.

28. Schmitt NM, Nicholson WK, Schmitt J. The association of pregnancy and the development of obesity-results of a systematic review and meta-analysis on the natural history of postpartum weight retention. Int J Obes. 2007;31:1642-51.

29. Pischon T, Boeing H, Hoffmann K, et al. General and abdominal adiposity and risk of death in Europe. N Engl J Med. 2008;359: 2105-20.

30. Fraser GE. Diet, life expectance, and chronic diseases: studies of Seventh-day Adventists and other vegetarians. Oxford: Oxford University Press; 2003. 